\title{
A ruptured cornual pregnancy: a case report
}

\section{Hind Ennasser*, Jamal Eddine Raoudi, Hafsa Taheri, Hanane Saadi, Ahmed Mimouni}

Department of Obstetrics and Gynecology, Mohammed VI University Hospital Center, Oujda, Morocco

Received: 07 July 2020

Accepted: 05 August 2020

\section{*Correspondence:}

Dr. Hind Ennasser,

E-mail: hindennasser@gmail.com

Copyright: (c) the author(s), publisher and licensee Medip Academy. This is an open-access article distributed under the terms of the Creative Commons Attribution Non-Commercial License, which permits unrestricted non-commercial use, distribution, and reproduction in any medium, provided the original work is properly cited.

\begin{abstract}
A cornual gestation is a rare form of ectopic gestations accounting for $2-4 \%$ of all tubal pregnancies with a high rate of mortality among to $2 \%-2.5 \%$. A 25 years old woman prima gravida was presented to the obstetrical emergency department with 8 weeks amenorrhea, lower abdominal pain and vaginal bleeding. A clinical diagnosis of ectopic pregnancy was made and confirmed using Ultrasonography and serum beta-hCG test. On laparotomy exploration authors found a left cornual ruptured ectopic pregnancy then authors made a left cornual resection with left salpingectomy. There were no postoperative complications.
\end{abstract}

Keywords: Cornual gestation, Ectopic pregnancy, Laparotomy, Tubal pregnancy

\section{INTRODUCTION}

Cornual or interstitial pregnancies are rare, represent $2 \%$ of ectopic pregnancies. ${ }^{1}$ It develops in the interstitial portion of the fallopian tube invading through the uterine wall. $^{2}$ The fact that the myometrium is quite distensible, thus its rupture is often later than other tubal pregnancies namely between 7-12 weeks of gestation with a mortality rate up to $2 \% .^{3}$ Here authors report a case of ruptured corneal pregnancy and profound haemorrhage occurred.

\section{CASE REPORT}

A 25 years old woman prima gravida, was presented to the obstetrical emergency department with 8 weeks amenorrhea, lower abdominal pain and vaginal bleeding from 2 days ago.

On general examination, the patient was conscious, but she was uncomfortable and irritable. Her blood pressure was $100 / 60 \mathrm{mmHg}$, pulse 114 beats/min, and she was afebrile.

In the abdominal examination there was tenderness without distention. Pelvic examination revealed a minima-bleeding coming from a closed cervix and positive cervical excitation tenderness. The pouch of Douglas was very painful.

Transabdominal 2-dimensional ultrasound revealed an empty uterus with a thickened endometrium and huge collection in pouch of Douglas, also in Morison's pouch. The pregnancy blood test was positive.

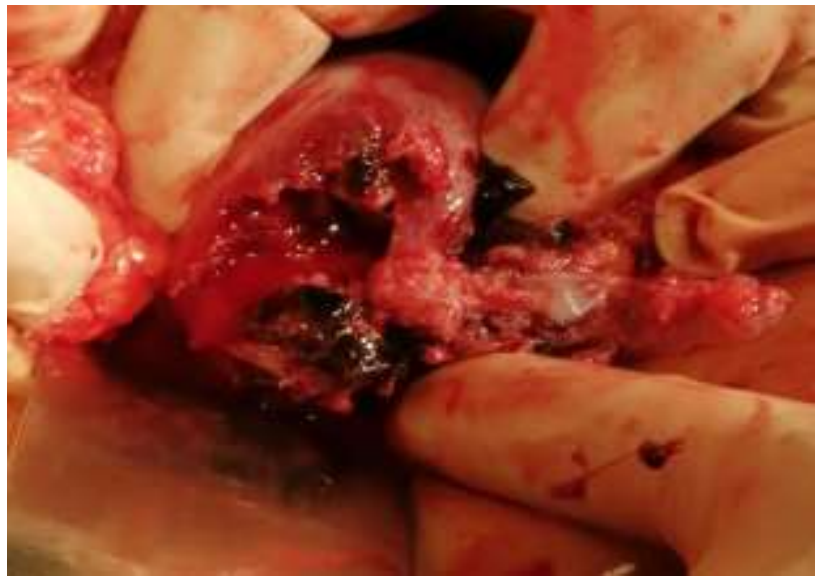

Figure 1: Intraoperative view of left cornual rupture. 


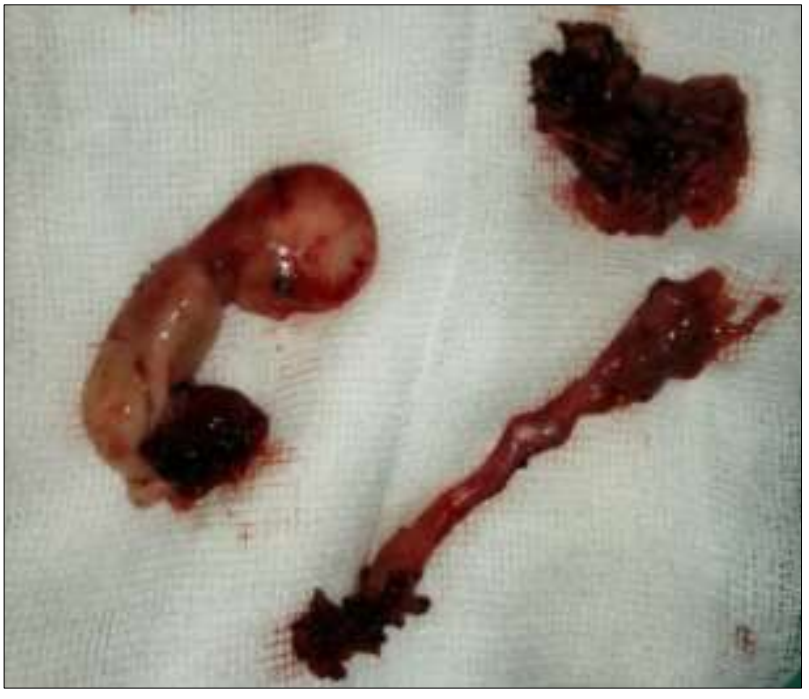

Figure 2: Fetus with salpingectomy and a cornual resection.

Authors realized an abdominal exploration and found a hemoperitoneum of great abundance. The uterus on the left side of the cornu was found ruptured, whereas the foetus-approximately $1.5 \mathrm{~cm}$ in length-was found in the peritoneal cavity (Figure 1, 2).

So, authors made up the left cornual resection with left salpingectomy. The postoperative period was uncomplicated and she was discharged home on the sixth day.

\section{DISCUSSION}

Cornual pregnancy accounts for $2-4 \%$ of ectopic pregnancies and is said to have a mortality rate in the range of $2.0-2.5 \% .^{1}$ This high rate of mortality is due to the late misdiagnosis and the speed of haemorrhage that's way it's important to diagnose cornual pregnancy before it ruptures.

Corneal or interstitial pregnancy is located in the intrauterine portion of the fallopian tube. This part of the fallopian tube is about 1 to $2 \mathrm{~cm}$ in length and $0.7 \mathrm{~cm}$ in width. ${ }^{4}$

The risk factors are; assisted reproductive techniques, previous tubal pregnancies, tubal surgeries, a history of pelvic inflammatory disease and sexually transmitted diseases. ${ }^{1}$ The clinical presentation of corneal pregnancy depends on it's being ruptured or not. In unruptured cases the patient presents an abdominal pain with or without vaginal bleeding with a history of abdominal pain a few days ago. As for ruptured cases authors find a severe abdominal pain and hemodynamic instability.

The diagnosis is based on the quantitative HCG assay and ultrasonography.
On ultrasonography imaging authors find an empty uterine cavity with identification of a gestational sac which is separate from the uterine cavity, the myometrial thinning of less than $5 \mathrm{~mm}$ around the gestational sac. The Doppler study show increase vasculature around the gestational sac "ring of fire", 5,6

The management of cornual pregnancy depend to different conditions; hemodynamic status, gestational age, presence of rupture, fertility desire $\beta$ hCG level. In unruptured cornual pregnancy, injection of methotrexate in the blood or directly in the cornual gestation sac can be proposed or a laparoscopic corne resection. In ruptured cases cornuotomy, cornual resection with salpingectomy and more radically a sub total hysterectomy. ${ }^{7,8}$ Uterine artery ligation may help to conserve the uterus in ruptured cornual ectopic. ${ }^{9}$ In this case, the cornua was founded largely ruptured with massive hemorrhage in the abdominal cavity, a cornual resection with salpingectomy was done.

\section{CONCLUSION}

Cornual pregnancy is a very rare and constitutes an obstetrical emergency It poses a significant diagnostic and a therapeutic challenge. Early diagnosis and appropriate management are the most important issues to avoid rupture of a cornual pregnancy with massive bleeding.

\section{Funding: No funding sources \\ Conflict of interest: None declared \\ Ethical approval: Not required}

\section{REFERENCES}

1. Tulandi T, AI-Jaroudi D. Interstitial pregnancy: results generated from the society of reproductive surgeons registry. Obstet Gynecol. 2004;103:47-50.

2. Shendy M, Atalla R. Modern management of cornual ectopic pregnancy, 2011. Available at: http://www.intechopen.com/books. Accessed on $07^{\text {th }}$ April 2020.

3. Lau S, Tulandi T. Conservative medical and surgical management of interstitial ectopic pregnancy. Fertil Steril. 1999;72:207-15.

4. Maowad NS, Mahajan ST, Moinz MD, Tayler SE, Hurd WW. Current diagnosis and treatment of interstitial pregnancy. Am J Obstet Gynaecol. 2010;202:15-29.

5. Abraham D, Silkowski C, Odwin C. Emergency Medicine Sonography: Pocket Guide to Sonographic Anatomy and Pathology. Jones Bartlett Learning; $1^{\text {st }}$ ed; 2009:264-227.

6. Faraj R, Steel M. Management of cornual (interstitial) pregnancy. Royal College of Obstet Gynaecol. 2007;9:249-55.

7. Hwang J, Lee J, Lee N, Lee L. Open cornual resection versus laparoscopic cornual resection in patients with interstitial ectopic pregnancies. 
European J Obstet Gynaecol Reproduct Biol. 2011;156:78-82.

8. Lee E, Hahn H, Park B, Ro D, Kim J, Kim Y. Single-port laparoscopic cornual resection for a spontaneous cornual ectopic pregnancy following ipsilateral salpingectomy. Fertil Steril. 2011;96(2):106-9.

9. Khawaja N, Walsh T, Gill B. Uterine artery ligation for the management of ruptured cornual ectopic pregnancy. Eur J Obstet Gynecol Reprod Biol. 2005;118:269.

Cite this article as: Ennasser H, Raoudi JE, Taheri $\mathrm{H}$, Saadi H, Mimouni A. A ruptured cornual pregnancy: a case report. Int J Reprod Contracept Obstet Gynecol 2020;9:3870-2. 